\title{
PALABRAS EN OCASIÓN DE LA ENTREGA DEL DOCTORADO HONORIS CAUSA A FRANZ HINKELAMMERT
}

\author{
Estela Fernández Nadal
}

\begin{abstract}
Texto de la conferencia pronunciada por la Dra. Estela Fernández Nadal en el acto académico de entrega del Doctorado Honoris Causa de la Universidad de Cuyo al Dr. Franz Hinkelammert, realizado en la Sede de la Universidad Nacional de Costa Rica, el 2 de diciembre del 2015.
\end{abstract}

El filósofo, teólogo y economista Franz Josef Hinkelammert nació en Alemania en 1931. La experiencia del nazismo influyó fuertemente en él, marcándole con la vivencia de crecer en una sociedad movilizada por la guerra y bajo un régimen político totalitario. Estudió Economía en la Universidad Libre de Berlín, donde se doctoró en esa disciplina, y realizó estudios de posgrado en el Instituto de Europa Oriental. En esos años, a la par de su formación neoclásica y de su especialización en la economía soviética y de Europa del Este, comenzó a frecuentar de forma autodidacta la bibliografía clásica marxista. Ya desde esa etapa empezó a interesarse por el contenido ideológico presente en las diversas escuelas de teoría económica.

En efecto, por esos años el joven Hinkelammert se interesó por desentrañar lo que, más allá del agnosticismo declarado de los dirigentes comunistas, él interpretaba como una teología implícita en la idea de la planificación socialista. Este descubrimiento despertó su interés por escudriñar la presencia del mismo tipo de ideologías en las economías occidentales. Una osada comparación entre las proyecciones utópicas de ambos modelos lo llevó a la sorprendente conclusión de que existían características análogas en la forma en la cual la teoría neoclásica concebía el equilibrio general y la manera en que los economistas soviéticos pensaban el comunismo.

Radicado en Santiago de Chile a partir de 1963, vivió en el país hermano durante los años de la experiencia de construcción del socialismo, liderada por Salvador Allende. Allí desempeñó una relevante labor académica: fue profesor de la Universidad Católica de Chile, del ILADES (Instituto Latinoamericano de Doctrina y Estudios Sociales) y miembro del CEREN (Centro de Estudios de la Realidad Económica Nacional). 
La experiencia vital y académica de su etapa chilena (1963-1973) fue sumamente importante en la trayectoria intelectual posterior de Hinkelammert. Esos años de profunda revulsión social y teórica lo pusieron en contacto con una realidad diferente a la europea y a la soviética, así como también con desarrollos teóricos no transitados en las academias del centro. En particular, Hinkelammert descubrió en Chile la Teología de la liberación y la Teoría de la dependencia. Desde entonces, forjó una mirada comprometida con América Latina, que no abandonaría nunca.

El terrorismo de Estado que se desató a partir del golpe militar de 1973 lo obligó a regresar a Alemania, donde permaneció un par de años hasta instalarse, primero provisoriamente, en Honduras y luego, ya de forma definitiva, en Costa Rica, en 1976. Allí fundó el Departamento Ecuménico de Investigaciones, donde realizaría su trabajo durante treinta años.

A partir de la interrupción violenta del proceso democrático chileno, Hinkelammert centró sus análisis en la alianza entre libre mercado y dictaduras totalitarias. $\mathrm{Su}$ tesis plantea que, de la mano de Pinochet, Chile fue el laboratorio de la primera experiencia neoliberal, que luego se extendería por América Latina y por el mundo noratlántico. Igual que en Chile, en todas partes la ideología neoliberal se asociaba a una teología extremadamente violenta, dispuesta a justificar la matanza indiscriminada de militantes, estudiantes, artistas e intelectuales. Economía y teología volvían a darse la mano, mostrando las complejas relaciones de dominación que unían por entonces al cielo y a la tierra.

Esta línea de investigación desembocó en la recuperación de la categoría marxiana de fetichismo, a la que Hinkelammert interpretó como un fenómeno inherente a la naturaleza humana. Esta es finita y vulnerable, pero está, al mismo tiempo, atravesada por un anhelo de infinitud, que solo puede encontrar expresión a través de la creación de dispositivos abstractos. Como bien descubrió Marx, el mercado es uno de tales mecanismos, pero no es el único. Otras objetivaciones de la actividad humana se separan del mismo modo de su productor y se autonomizan; tal como sucede con el lenguaje, la ciencia, las leyes y, en definitiva, las instituciones. Todas ellas conforman un mundo de mediaciones abstractas, necesarias para la vida, pues nos permiten pensar y actuar en términos universales, esto es, más allá de la experiencia humana directa. Sin embargo, esas inevitables mediaciones abstractas, creadas para permitir el desarrollo humano, tienden a independizarse del hombre y a someterlo; incluso, pueden convertirse en poderes que matan.

Frente a ellos, Hinkelammert sostiene prioridad de la vida como criterio primero y elemental de verdad y de racionalidad. Se trata de un criterio de alcance intersubjetivo, que encierra una comprensión del ser humano como una totalidad socionatural, cuya supervivencia exige su integración con los demás hombres y con la naturaleza a través de la división social del trabajo y del metabolismo con el medio. 
En el fondo del fenómeno del fetichismo está la cuestión de la autonomización de la racionalidad formal y abstracta, la racionalidad de los medios, que se ha separado e independizado de la racionalidad material, de los fines, hasta el punto de suplantarla y subordinarla. Esta preeminencia atraviesa la estructura categorial de todas las ideologías políticas de la Modernidad y es la causa de sus derivaciones totalitarias, características del siglo XX.

La explicación de este fenómeno lleva a Hinkelammert a analizar el funcionamiento de las utopías, a las cuales concibe, igual que Kant, como ideas reguladoras de la razón. Así entendidas, las utopías constituyen el marco trascendental de condiciones de posibilidad de lo posible, pero son incongruentes con cualquier realización social o política efectiva. El problema radica, precisamente, en el olvido del carácter trascendental de las utopías, que origina una forma contradictoria de relacionarse con lo imposible. Según la misma, las metas utópicas, imposibles en tanto superan los límites de la condición humana, devendrían posibles (realizables empíricamente) a partir de una aproximación asintótica proyectada al infinito.

El mito moderno del progreso es el sustrato sobre el que se levanta ese uso acrítico de la razón utópica. Como consecuencia del mismo, las utopías, en lugar de iluminar las posibilidades auténticamente efectivas, plantean metas imposibles a nivel táctico, en nombre de las cuales se prohíbe y combate cualquier crítica a la realidad presente, que pasa a considerarse como un momento necesario en el tránsito hacia la perfección final.

La crítica de la razón utópica de Hinkelammert reconoce a las utopías la capacidad de interpelar el proceso en curso, a fin de intervenirlo y transformarlo; pero, al mismo tiempo, plantea la necesidad de reformular los proyectos sociales y políticos, entendiendo la acción política como una aproximación práctica a una utopía siempre sujeta a reformulación y nunca factible en términos empíricos.

A partir de los años noventa, tras la caída del muro de Berlín, el colapso del mundo socialista y el triunfo arrasador del capitalismo, Hinkelammert analiza las consecuencias sociales y culturales de la instalación de lo que llama la "lógica de la única alternativa". Considera a la globalización como una estrategia de acumulación capitalista, que consigue avanzar e imponerse gracias a que se recubre de una particular "espiritualidad". Ese entramado espiritual, que acompaña la estrategia de la globalización capitalista, posee, al igual que otras idealizaciones anteriores, el carácter de una utopía no sometida a la crítica. El neoliberalismo retoma el mito del mercado como institución sacralizada, especie de divinidad despojada de carácter trascendente y convertida en un principio inmanente de funcionamiento perfecto, que realiza automáticamente el interés general. Se trata de una utopía, que, en nombre de la Realpolitik, demoniza todas las demás utopías y combate las formas de resistencia que se le oponen, socavando las posibilidades de frenar la irracionalidad por ella desencadenada y de evitar el suicidio colectivo de la humanidad. 
De allí se explica que Hinkelammert otorgue gran importancia a pensar y acompañar teóricamente formas de resistencia frente al proceso en curso, como espacios de lucha donde sea posible producir el retorno del sujeto aplastado y reprimido por la estrategia de globalización neoliberal, así como también a despertar de la conciencia en torno a la necesidad de desarrollar una nueva espiritualidad humana basada en la convivencia, en el respeto al otro y a la naturaleza.

Para Hinkelammert esa lógica destructora de la utopía del mercado total se manifiesta también en el nivel político. La absolutización de la relación mercantil no solo amenaza las bases de sustentación de la vida en todas sus formas; también, por la vía de la conformación de un poder económico mundial de carácter extraparlamentario y no sometido al control público -el poder de las burocracias privadas- ha socavado la misma democracia liberal, devenida en mero correlato político del mercado como institución económica.

Frente a esa amenaza, es necesario reelaborar el concepto de "democracia", en el sentido de incorporar en ella la capacidad de intervenir los mercados a fin de someter los intereses de las burocracias privadas al interés primero de la vida.

Como un complemento de su crítica de la razón utópica, en sus trabajos de la última década, Hinkelammert ha abordado la "crítica de la razón mítica". A partir de la puesta en sospecha el concepto de "secularización" ha postulado la existencia de un continuidad histórica profunda entre cristianismo y Modernidad y, en forma más específica, entre el capitalismo y las formas ortodoxas y represivas de la religiosidad cristiana. Sin el "acontecimiento Jesús", eje de la matriz cristiana, no hubiera sido posible el hecho decisivo de la Modernidad, a saber, que Dios se hiciera hombre. Hay vasos comunicantes entre ambos momentos históricos, los cuales permiten entender la sobrevivencia, bajo ropajes profanos, de antiguos resortes míticos que impulsan secretamente las dinámicas de la razón instrumental. A lo largo de todo el proceso, esos mitos han funcionado ambiguamente: muchas veces han justificado el aplastamiento del sujeto y legitimado su subordinación a los poderes de turno, pero también han servido (y pueden servir hoy) para la afirmación del sujeto frente a las instituciones.

La prioridad del sujeto, como fuente de resistencia que enfrenta a los productos del trabajo humano objetivados, y de la vida, como criterio material de verdad y racionalidad, hacen de Hinkelammert un pensador profundamente original, que postula un universalismo ético y político de carácter material y concreto, acorde a la condición del ser humano real, que está concreta y corporalmente unido a los otros seres humanos y a la naturaleza, a un punto tal que no puede vivir sin ellos. "Asesinato es suicidio" es el lema que condensa la concepción hinkelammertiana del sujeto: una compleja realidad intersubjetiva, de cuya emergencia y afirmación depende la vida, tanto de cada individuo como de la especie.

De lo dicho se desprende claramente la relevancia y solidez de la crítica de Hinkelammert a la racionalidad moderna en general, y en particular a la culminación 
de esa matriz en el actual proceso de globalización tardo-capitalista. Una crítica contundente, que no solo alerta sobre los efectos destructores del actual proceso globalizador en el plano económico, social, ecológico y los consecuentes riesgos que ese deterioro implica, a su vez, para los propios procesos democráticos latinoamericanos, sino que también alienta y orienta la búsqueda de alternativas. Frente a los fenómenos de la exclusión y la privación de los medios de vida de amplios y crecientes sectores de la población mundial, y frente al progresivo deterioro del medio ambiente y de la convivencia humana, esas posibles alternativas deben basarse en el reconocimiento de la vida, de los seres humanos y de la naturaleza, como único criterio válido de discernimiento y verdad.

Alejado del DEI a partir de 2007, Franz Hinkelammert continúa actualmente su tarea de investigación y docencia en Costa Rica, donde mantiene vínculos institucionales con la Universidad de Costa Rica (UCR), donde dicta periódicamente seminarios de posgrado, y fundamentalmente con la Universidad Nacional de Costa Rica (UNA). En 2008 Hinkelammert fundó con un puñado de colaboradores el Grupo de Pensamiento Crítico (GPC), asociación sin fines de lucro formada por numerosos profesores, investigadores y estudiantes costarricenses, a los que se fueron uniendo otros latinoamericanos. Muchos de sus integrantes habían participado en décadas anteriores del "Seminario de Investigadores", realizado anualmente en el DEI por un periodo de cuatro meses. Este en espacio multidisciplinario -donde convergen economistas, filósofos, sociólogos, juristas, educadores, escritores y artistas- nació en estrecha coordinación con la Cátedra de Pensamiento Crítico "Franz Hinkelammert", fundada en el año 2007 en la Universidad Nacional (UNA), y ha podido afianzarse y desarrollarse gracias al apoyo académico de las autoridades de la casa, brindando actualmente una amplia plataforma para proseguir el trabajo a futuro. Desde su fundación, el GPC y la Universidad Nacional (UNA) han organizado cuatro encuentros, siempre con una periodicidad bianual (2008, 2010, 2013 y 2014), estando prevista la próxima reunión para el año próximo.

La Universidad Nacional ha sido, además, el primer centro de educación superior en otorgarle a Hinkelammert el Doctorado Honoris Causa, hecho que tuvo lugar en el 2002. Con posterioridad, el maestro recibió la misma distinción de la Universidad UniBrasil de Curitiba en el 2005, de la Universidad Bolivariana de Chile en el 2007 y de la Universidad de La Habana en el 2012. Otros premios importantes que conviene retener son, en el 2003, cuando el Ministerio de Cultura de Costa Rica le entregó el Premio Nacional "Aquileo Echeverría"; y en junio del 2006, cuando la República Bolivariana de Venezuela lo galardonó con la entrega de la Primera Edición del Premio Libertador al Pensamiento Crítico.

Sobre su amplia labor de magisterio, cabe destacar sumariamente que, además de su fecunda labor académica y de formación de discípulos en América Latina (Chile, Costa Rica, Honduras, Brasil, Colombia, México, Argentina, Bolivia, 
Nicaragua, El Salvador, Uruguay, etc.) ha sido profesor asiduo en numerosas universidades europeas, particularmente de Alemania, España y Suiza.

Finalmente, resta agregar que, entre las obras más importantes de Hinkelammert se encuentran: Dialéctica del desarrollo desigual (1970, 1983), Ideologías del desarrollo y dialéctica de la historia (1970), Ideologías del sometimiento (1977), Las armas ideológicas de la muerte. El discernimiento de los fetiches: capitalismo y cristianismo (1977), Crítica de la razón utópica $(1983,2002)$, Democracia y totalitarismo (1987, 1990), Cultura de la esperanza y sociedad sin exclusión (1995, 1999), Determinismo, caos, sujeto. El mapa del emperador (1996), El grito del sujeto (1998), El huracán de la globalización (1999), El nihilismo al desnudo. Los tiempos de la globalización (2001), El retorno del sujeto reprimido (2002), El asalto al poder mundial y la violencia sagrada del Imperio (2003), El sujeto y la ley (2003, 2006), Hacia una crítica de la razón mítica (2007), Lo indispensable es inútil. Hacia una espiritualidad de la liberación (2010), La maldición que pesa sobre la ley. Las raíces del pensamiento crítico en Pablo de Tarso (2010, 2013).

Con Ulrich Duchrow es coautor de La vida o el capital. Alternativas a la dictadura global de la propiedad (2003), y con Henry Mora, de Coordinación social del trabajo, mercado y reproducción de la vida humana (2001), Hacia una economía para la vida (2005, 2008, 2009 2013, 2014) y Economía, sociedad y vida humana. Preludio a una segunda crítica de la economía política (2009).

\title{
Bibliografía $^{1}$
}

\author{
Por Carlos Molina Velázquez
}

\section{Libros}

Der Wachstumsprozeß in der Sowjetwirtschaft. Eine Untersuchung der Produktionsstruktur, des Lenkungsprozesses und des Volkseinkommens, Editorial Dunker \& Humblot, Berlin, 1961. Das Bild der Wirtschaft der Bundesrepublik, Berlin, 1964.

Economía y revolución, Editorial del Pacífico, Santiago de Chile, 1967, 192 pp.

Plusvalía e interés dinámico. Un modelo para la teoría dinámica del capital, Editorial Ensayos Latinoamericanos, Santiago de Chile, 1969, 191 pp.

Problemas del desarrollo, ILADES, Santiago de Chile, 1969, Mimeo, 131 pp.

Dialéctica del desarrollo desigual, Amorrortu Editores, Buenos Aires, 1970 [1974].

Dialéctica del desarrollo desigual, Ediciones Universitarias de Valparaíso, Santiago de Chile, 1972. Dialéctica del desarrollo desigual, EDUCA, San José, 1983, 348 pp.

El subdesarrollo latinoamericano. Un caso de desarrollo capitalista, Ediciones Nueva Universidad, Universidad Católica de Chile, Editorial Paidós, Buenos Aires, 1970, 134 pp.

Ideologías del desarrollo y dialéctica de la historia, Ediciones Nueva Universidad, Universidad Católica de Chile, Editorial Paidós, Buenos Aires, 1970 [1972, 1974], 306 pp.

$1 \quad$ Algunas de las referencias a la obra de Franz Hinkelammert se encuentran incompletas debido a la dificultad para acceder a los textos, razón por la cual solicitamos las disculpas del caso. 
La teoría clásica del imperialismo, el subdesarrollo y la acumulación socialista, Ediciones Nueva Visión, Buenos Aires, 1973.

"La teoría clásica del imperialismo, el subdesarrollo y la acumulación socialista", en Cuadernos de la Realidad Nacional, N. ${ }^{\circ}$ 4, Santiago de Chile, 1970, 24 pp.

"La teoría clásica del imperialismo, el subdesarrollo y la acumulación socialista", en Economía política en la Unidad Popular. Materiales de los Cuadernos de la Realidad Nacional (1970-1973), presentación a cargo de Manuel Antonio Garretón, Editorial Fontanella, Barcelona, 1975, 15-51 pp.

Die Radikalisierung der Christdemokraten, Rotbuch-Verlag, Berlin, 1976, 142 pp.

Ideología de sometimiento, EDUCA-DEI, San José, 1977, 176 pp.

Las armas ideológicas de la muerte, EDUCA-DEI, San José, 1977 [1981, 2. edición ampliada y revisada, con introducción de Pablo Richard y Raúl Vidales, 325 pp.], 254 pp.

Las armas ideológicas de la muerte, Ediciones Sígueme, Salamanca, 1978.

As armas ideológicas da morte, Edições Paulinas, São Paulo, 1983.

Die Ideologischen Waffen des Todes, Edition Liberación-Edition Exodus, Freiburg (Schweiz)/ Münster, 1985.

The Ideological Weapons of Death. A Theological Critique of Capitalism. Traducción del español de Phillip Berryman, con prólogo de Cornel West, Orbis Books, Maryknoll, New York, 1986.

La coherencia lógica de la construcción de una mercancía patrón, Mimeo, Tegucigalpa, 1980, 140 pp.

Documento de Estudio. Socialdemocracia y Democracia Cristiana: Las reformas sociales y sus limitaciones, INCEP/REP/3-81, Honduras, 1981.

Crítica a la razón utópica, II Encuentro de Científicos Sociales y Teólogos, Mimeo, San José, 1983, 163 pp.

Crítica a la razón utópica, DEI, San José, 1984, 275 pp.

Crítica à razão utópica, Edições Paulinas, São Paulo, 1986, 307 pp.

Crítica de la razón utópica, 2. edición, DEI, San José, 1990, 275 pp.

Kritik der utopischen Vernunft. Eine Auseinandersetzung mit den Hauptströmungen der modernen Gesellschaftstheorie, Luzern/Mainz, 1994.

Crítica de la razón utópica [edición ampliada y revisada], Desclée de Brouwer, Bilbao, 2002.

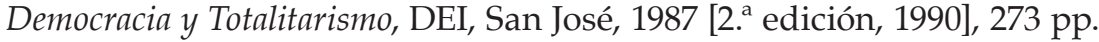

Democracia y totalitarismo, Amerindia, Chile, 1987.

La deuda externa de América Latina: el automatismo de la deuda, DEI, San José, 1988, 1990, 110 pp.

A dívida externa da América Latina. O automatismo de dívida, Vozes, Petrópolis, 1989.

Il debito estero dell' AmerIca Latina. l'automatismo del debito, La Piccola Editrice, Cellen (VT), 1990.

Teología del mercado total: ensayos económico-teológicos, HISBOL, La Paz, 1989 [1992, primera reimpresión], 103 pp.

La fe de Abraham y el Edipo occidental, DEI, San José, 1989 [Segunda Edición ampliada: 1991, 2000], 101 pp.

Der Glaube Abrahams und der Ödipus des Westens. Opfermythen im christlichen Abendland, Edition Liberation, Münster, 1989.

Ecuador, coyuntura política, 1990.

El capitalismo al desnudo, Editorial El Búho, Bogotá, 1991.

Sacrificios humanos y sociedad occidental: Lucifer y la bestia, DEI, San José, 1991 [1993].

Cultura de la esperanza y sociedad sin exclusión, DEI, San José, 1995.

Kultur der Hoffnung. Für eine Gesellschaft ohne Ausgrenzung und Naturzerstörung, Luzern/ Mainz, 1999. El mapa del emperador. Determinismo, caos, sujeto, DEI, San José, 1996. 
El grito del sujeto. Del teatro-mundo del evangelio de Juan al perro-mundo de la globalización, DEI, San José, 1998.

Der Schrei des Subjekts. Vom Welttheater des Johannesevangeliums zu den Hundejahren der Globalisierung, Luzern, 2001.

El huracán de la globalización, DEI, San José, 1999 [Franz Hinkelammert es el editor/compilador y hay tres artículos suyos en el libro, incluyendo el prólogo].

Ensayos, Editorial Caminos, La Habana, 1999.

El nihilismo al desnudo: los tiempos de la globalización, Editorial Lom, Santiago de Chile, 2001.

El retorno del sujeto reprimido, Universidad Nacional de Colombia, Bogotá, 2002 [2003].

El asalto al poder mundial y la violencia sagrada del imperio, DEI, San José, 2003.

La violencia sagrada del imperio: el asalto al poder mundial, DEI-Justicia y vida, Bogotá, 2003.

El sujeto y la ley: el retorno del sujeto reprimido, EUNA, San José, 2003.

Solidaridad o suicidio colectivo, Ambientico, San José, 2003.

Solidaridad o suicidio colectivo, Ambientico ediciones, Universidad de Granada, Granada, 2005.

Hacia una crítica de la razón mítica. El laberinto de la modernidad. Materiales para la discusión, Arlekín, San José, 2007.

Hacia una crítica de la razón mítica: El laberinto de la modernidad, Editorial Driada, México D.F., 2008, 253 pp.

La maldición que pesa sobre la ley. Las raíces del pensamiento crítico en Pablo de Tarso, Arlekín, San José, 2010.

Lo indispensable es inútil: hacia una espiritualidad de la liberación, Arlekín, San José, 2012.

¿Quieren el mercado total? El totalitarismo del mercado, inédito [contiene, con algunas modificaciones, tres artículos publicados antes, en El sujeto y la ley [capítulo III], Lo indispensable es inútil: hacia una espiritualidad de la liberación [capítulo IV] y en Realidad. Revista de Ciencias Sociales y Humanidades, N. 132 [capítulo V] 2015.

\section{Libros y artículos en coautoría, entrevistas}

Con Hugo Villela: "Autogestión, participación y democracia socialista”, en Revista Mensaje, 20 (199), junio, 1971, pp. 218-224.

Con Ariel Dorfman: "Cultural repression in Chile", en Jerman, William, Repression in Latin America, Spokesman Books, Nottingham, 1975, pp. 82-97.

Con Dorothee Sölle (entrevistadora): “Unser Kampf hat seine tiefsten Wurzeln im Glauben an die gute Schöpfung", en Sölle Dorothee, Theo Christiansen und Johannes Thiele (ed.), Dorothee Sölle im Gespräch mit Franz Hinkelammert über Gesetz und Befreiung, Lieben und Arbeiten, Glück und Reich Gottes, Kreuz-Verlag, Stuttgart, 1988, pp. 201-216.

Con Hugo Assmann: A idolatria do Mercado. Ensaio sobre economia e teología, Vozes, São Paulo, 1989, 456 pp. [L'idolatrie du marché: critique théologique de l'economie de marché, traduction du portugais (Brésil) par Christine et Luc Durban et de l'espagnol par René Grasset, Les Éditions du Cerf, Paris, 1993, 378 pp.]. Hay siete artículos/conferencias de Hinkelammert, los cuales parece que fueron editados y publicados, en forma de cuatro ensayos, en El mapa del emperador:

"Economía y teología: el Dios de la Vida y la vida humana", también en Democracia y totalitarismo.

"Una historia del cielo: problemas del fundamentalismo cristiano", también en Democracia y totalitarismo.

"Afirmación de la vida y sacrificios humanos". 
"Del mercado total al imperio total", también en Democracia y totalitarismo.

"El significado de los criterios de decisión económica".

"La teología del imperio", corresponde al publicado en Pasos, $N^{\circ} 15$, Enero/Febrero, 1988, DEI, San José, pp. 21-18.

"Problemas actuales de Economía Política", también en Democracia y totalitarismo.

Con Hugo Assmann: Götze Marka, Patmos, Düsseldorf, 1992.

Volumen colectivo: América Latina: Resistir por la vida (documento de trabajo), REDLA-CPID, DEI, San José, 1993.

“Entrevista a F. Hinkelammert”, en Gomáriz, Enrique y Vergara, Jorge, “Teoría, epistemología y poder en la sociología latinoamericana de los noventa. Un análisis desde la crisis teórica de la sociología", en Fermentum, 6-7, enero-agosto, 1993.

Con Norbert Arntz: “Das Überleben aller Menschen sichern”, in Orientierung, N. os 15/16, 58 Jahrgang, 15/31, Zürich, August, 1994, seite 170.

Con Oswaldo León (entrevistador): "El mundo de la globalización es ingobernable”, en Revista del Sur, N.o 72, Uruguay, 1997 [http://www.feeye.uncu.edu.ar/web/epistemologia/ Lineadetiempo/Documentos/Hinkelammert/entrevista/central.html].

Con Pablo Richard y Wim Dierckxsens: "Presentación" de "La vuelta del sujeto reprimido frente a la estrategia de la globalización (Síntesis del encuentro de cientistas sociales y teólogos/as: La problemática del sujeto en el contexto de globalización)", en Pasos, N. 87 , DEI, San José, enero/febrero, 2000, pp. 1-3.

Con Henry Mora: Coordinación social del trabajo, mercado y reproducción de la vida humana. Preludio a una teoría crítica de la racionalidad reproductiva, DEI, San José, 2001.

Con Germán Gutiérrez, Dorothee Sölle, Raúl Fornet-Betancourt, Norbert Arntz, Helio Gallardo, Benjamín Forcano, Manuel García Guerra, Enrique Dussel y Henry Mora: "Entrevistas y conversaciones con Franz J. Hinkelammert" (entrevistas, conversaciones y cuestionario), en Duque, José y Gutiérrez, Germán (eds.), Itinerarios de la razón crítica: Homenaje a Franz Hinkelammert en sus 70 años, DEI, San José, 2001, pp. 17-206. La entrevista realizada por Henry Mora [“La actualidad de la economía política”, pp. 151-184] fue publicada también como "Entrevista a Franz J. Hinkelammert: claves de un pensamiento crítico", en Herrera Flores, Joaquín (Ed.), El vuelo de Anteo. Derechos humanos y crítica de la razón liberal, Desclée de Brouwer, Bilbao, 2000, pp. 267-303, y (con este último título) en El nihilismo al desnudo, pp. 255-297.

Con Ulrich Duchrow: Leben ist mehr als Kapital. Alternativen zur globalen Diktatur des Eigentums, Oberursel, Frankfurt, 2002.

Con Ulrich Duchrow: La vida o el capital. Alternativas a la dictadura global de la propiedad, DEI, San José, 2003.

Con Henry Mora Jiménez: Hacia una economía para la vida [Prólogo de Rodrigo Carazo], DEI, San José, 2005.

Con Henry Mora Jiménez: Hacia una economía para la vida. Preludio a una reconstrucción de la economía, 2. edición, Editorial Tecnológica de Costa Rica, Cartago, 2008, 624 pp.

Con Henry Mora Jiménez: Hacia una economía para la vida. Preludio a una reconstrucción de la economía, Edición revisada y aumentada, Proyecto Justicia y Vida/ Casa de Amistad Colombo-Venezolana/ COMPROMISO, Bogotá, 2009.

Con Lilia Solano (entrevistadora): "Con los pobres de la tierra quiero yo mi suerte echar". Entrevista a Franz Hinkelammert, Editorial Buena Semilla, Bogotá, 2007. 
Con Henry Mora Jiménez: "Por una economía orientada hacia la vida", en América Latina en Movimiento, N. ${ }^{\circ}$ 430, Publicación internacional de la Agencia Latinoamericana de Información, año XXXII, II Época, Quito, 2008, pp. 8-13.

Con Henry Mora Jiménez: "Por una economía orientada hacia la reproducción de la vida", en Íconos. Revista de Ciencias Sociales, N. 33, FLACSO, Quito, 2009, pp. 39-49.

Con Henry Mora Jiménez: “Condiciones iniciales para una política de desarrollo y del medio ambiente: un enfoque a partir de los derechos concretos a la vida", en Ciencias económicas, 26 (1), 2008, pp. 55-71.

Con Henry Mora Jiménez: "Mitificación y sacralización de las relaciones sociales: la espiritualidad del mercado y el mito del poder", 2009.

Con Henry Mora Jiménez: Economía, sociedad y vida humana. Preludio a una segunda crítica de la economía política, Editorial UNGS-Altamira, Colección Lecturas de Economía Social N. ${ }^{\circ}$ 69, Buenos Aires, 2009.

Con Henry Mora Jiménez: "Pensamiento crítico y crítica de la economía política", en Pasos N. 150, julio/agosto, DEI, San José, 2010, pp. 16-25 [Corresponde a la ponencia homónima publicada por Henry Mora en Realidad. Revista de Ciencias Sociales y Humanidades, N. ${ }^{\circ}$ 132, abril-junio, 2012, UCA, San Salvador, pp. 251-265].

Con Estela Fernández Nadal y Gustavo David Silnik (entrevistadores): Teología profana y pensamiento crítico. Conversaciones con Franz Hinkelammert, CLACSO, Buenos Aires, 2012.

Con Henry Mora Jiménez: Economía, vida humana y bien común (25 reflexiones sobre Economía Crítica), Costa Rica, enero de 2013 [http://www.pensamientocritico.info/index.php/ libros/libros-de-franz-hinkelammert/espanol].

\section{Artículos (en revistas, partes de libros, ponencias)}

"Das Investitionskriterium in Theorie und Praxis der sowjetischen Wirtschaftspolitik" ("El criterio de inversión en la teoría y la praxis de la política económica soviética"), en Osteuropawirtschaft (Economía de Europa del Este), Heft 1, 1962.

"Einige Bemerkungen zur sowjetischen Vorstellung von der Konjunkturentwicklung im Kapitalismus", en Osteuropawirtschaft, Heft 4, 1962.

"Kommunismusbild und wirtschaftliches Handeln. Untersucht am Verhältnis von Wirtschaftsideologie. Wirtschaftstheorie und wirtschaftlicher Wirklichkeit in der sowjetischen Wirtschaftslehre", unveröffentlichtes Manuskript, Berlin, 1962.

"Die Wachstumsrate als Rationalitätskriterium" ("La tasa de crecimiento como criterio de la racionalidad"), en Osteuropawirtschaft, Heft 1, 1963.

"Neue wissenschaftliche Planungsmethoden" ("Nuevos métodos científicos de planificación"), en Osteuropa-Handbuch (Manual de Europa del Este), Hrgs. Werner Markert, Köln-Gras, 1963.

“El criterio de la inversión en la teoría y práctica de la política económica soviética”, en Apartado de la revista 'Cuadernos de Economía', N. 6, mayo-agosto, Santiago de Chile, 1965.

"La ideología de la economía", Ponencia en Seminario del Instituto de Estudios Políticos (IDEP), Santiago de Chile, junio, 1966, 18 pp.

“Ideología, mito y utopía", en Política y Espíritu, N. 299-301, Santiago de Chile 1967, , 32 pp.

"Dialéctica de los valores y epistemología de la acción", ponencia en Seminario del Instituto Latinoamericano de Desarrollo, ILADES, Santiago de Chile, 1968, 26 pp. 
"Dialéctica de los valores y epistemología de la acción", ponencia en Seminario de Teología, ILADES, Santiago de Chile, 1968, 7 pp.

"Marginalidad y lucha de clases", en Universidad y Desarrollo. Número Especial, Febrero, 1968, Ediciones CPU, Santiago de Chile, 8 pp. o 12 pp.

"Modelos de desarrollo", en América Latina Hoy, N. ${ }^{\circ}$ 2, 1968, Santiago de Chile, pp. 67-80.

"Reflexiones sobre la revolución marxista. A propósito de los 50 años de la Revolución Rusa", en Revista Mensaje, vol. 17, N. ${ }^{\circ}$ 166, Enero-Febrero, Santiago de Chile, 1968, pp. 13-18 (7 pp.)

"Instituciones cristianas y sociedad", en América Latina Hoy, N. ${ }^{\circ}$ 1, Enero-Marzo, Santiago de Chile, 1969, pp. 38-54.

"Las clases sociales en la sociedad capitalista y en la sociedad socialista", en Cuadernos de la Realidad Nacional, $\mathrm{N}^{\mathrm{O}}$ 1, Santiago de Chile, Universidad Católica de Chile, CEREN, Septiembre, 1969, pp. 119-161 (42 pp.)

“Teoría de la dialéctica del desarrollo desigual”, en Cuadernos de la Realidad Nacional, No 6, Especial [dedicado a "Dialéctica del desarrollo desigual. El caso latinoamericano"], Santiago de Chile, Universidad Católica de Chile, CEREN, Diciembre, 1970, pp. 15-220.

"Acumulación socialista, interés de clase del proletariado y alianzas de clase", en Tercer Mundo, $N^{\circ}$ 4, Santiago de Chile, 1971, pp. 22-55.

"Economía socialista e interés del proletariado. Discusión de criterios de la transformación", en Cuadernos de la Realidad Nacional, No Especial 10, Universidad Católica de Chile, CEREN, Santiago de Chile, Diciembre, 1971, pp. 9-48.

"El materialismo histórico", en Revista Mensaje, vol. 20, N.. 201, Santiago de Chile, Agosto, 1971, pp. 338-345 (8 pp.).

“Fetichismo de la mercancía, del dinero y del capital. La crítica marxista de la religión", en Cuadernos de la Realidad Nacional, N. 9 9, Santiago de Chile, 1971, pp. 3-28 (26 pp.).

"Fetichismo de la mercancía, del dinero y del capital. La crítica marxista de la religión", en Centro Crítico Universitario, Boletín Año 11, N. ${ }^{\circ}$ 5, Santiago de Chile, Junio, 1971, 33 pp.

"Problemas y perspectivas del socialismo en Chile", Cuadernos de la Realidad Nacional, 10 Especial, Santiago de Chile, 1971.

"Consideraciones sobre las alternativas del cambio de [las] estructuras económicas en Chile", en Cuadernos de la Realidad Nacional, No 14, Santiago de Chile, Octubre, 1972, pp. 175-185.

"La situación de la sexualidad dentro del materialismo histórico", en Cuadernos de la Realidad Nacional, No 12, Abril, Santiago de Chile, 1972, pp. 232-246, 265.

"Ciencia y mito en el análisis social". Comentarios de lectura, en Cuadernos de la Realidad Nacional, No 17, Santiago de Chile, Julio, Universidad Católica de Chile, CEREN, 1973, pp. 230-256.

"Condiciones y consecuencias de una política de redistribución de ingresos", en Cuadernos de la Realidad Nacional, N. 17 , Santiago de Chile, 1973, 26 pp.

"El significado de la ley del valor para la crítica marxista de la religión", en Cuadernos de la Realidad Nacional, N. ${ }^{\circ}$, Santiago de Chile, 1973, 18 pp.

"Las relaciones mercantiles en la sociedad socialista como cuestionamiento a la crítica marxista de la religión", en Cuadernos de la Realidad Nacional, No 17, julio, Santiago de Chile, Universidad Católica de Chile, CEREN, 1973, pp. 152-169. 
"Consideraciones sobre las alternativas del cambio de las estructuras económicas en Chile”, en Economía politica en la Unidad Popular. Materiales de los Cuadernos de la Realidad Nacional (1970-1973), presentación a cargo de Manuel Antonio Garretón, Editorial Fontanella, Barcelona, 1975, pp. 253-270.

"Economía socialista e interés del proletariado. Discusión de los criterios de la transformación", en Economía política en la Unidad Popular. Materiales de los Cuadernos de la Realidad Nacional (1970-1973), presentación a cargo de Manuel Antonio Garretón, Editorial Fontanella, Barcelona, 1975, pp.273-332.

"El credo económico de la comisión trilateral", en Hugo Assmann (ed.), Carter y la lógica del imperialismo, tomo I, EDUCA, San José, 1978, pp. 203-231.

"El Dios mortal: Lucifer y la Bestia. La legitimación de la dominación en la Tradición Cristiana", en Elsa Tamez/ Saúl Trinidad (editores), Capitalismo: violencia y anti-vida. La opresión de las mayorías y la domesticación de los dioses, tomo I, EDUCA, San José, 1978, pp. 199-313.

"La religión del imperio: el fetichismo en la publicidad actual", contribución al Seminario sobre Sociología de la Religión, UCA, San Salvador, 24-28 de julio de 1978.

"La afirmación de las estructuras de valores en nombre de la ciencia en la metodología de Max Weber, Revista Centroamericana de Economía, No 1, Tegucigalpa, 1979, pp. 98-128.

"La división social del trabajo y la reproducción de la vida humana", Postgrado en Economía y Planificación del Desarrollo, UNAH, Tegucigalpa, Mimeo, 1980.

"La metodología de Max Weber y la derivación de valores en nombre de la ciencia", en Epistemología y política, CINEP, Bogotá, 1980, pp. 125-158 (Actas del II Seminario del Grupo de Estudios de la CLACSO “Epistemología y política”, Bogotá, mayo de 1979). También publicado en Democracia y totalitarismo, pp. 81-112.

"Las raíces económicas de la idolatría: la metafísica del empresario", en Richard, Pablo (ed.), La lucha de los dioses, DEI, San José, 1980, pp. 195-229. También fue publicado en Las armas ideológicas de la muerte y probablemente corresponde a "La metafísica del empresario", Documento de trabajo para la Maestría en Sociología de la Universidad Iberoamericana, Febrero, 1981, 32 pp.

"Problemas actuales de la economía política", conferencia pronunciada en marzo de 1980 y publicada en Democracia y totalitarismo, 1980, pp. 3-12.

"Socialdemocracia y Democracia Cristiana: Las reformas sociales y sus limitaciones", en Assmann, Hugo y Hinkelammert, Franz (eds.), El Juego de los reformismos frente a la revolución en Centroamérica: materiales sobre la socialdemocracia, la democracia cristiana, el reformismo yanqui, Editorial DEI, San José, 1981 [hay otra edición sin fecha, 181 pp.], pp. 13-56.

“La absolutización de los valores”, en González Álvarez, Luis José (ed.), Temas de ética latinoamericana, Editorial El Búho, Bogotá, 1981, pp. 123-127 [tomado de Las armas ideológicas de la muerte, 1977, pp. 235-238]

“Comentario desde una perspectiva económico-social", en Equipo DEI, Juan Pablo II. Sobre el trabajo humano, DEI, San José, 1982, pp. 69-96.

"Condiciones estructurales para una política del desarrollo, del medio ambiente y de la paz", conferencia pronunciada el 5 de junio de 1982 y recogida en Democracia y totalitarismo, 1982, pp. 45-60.

"Du sollst keinen Gott neben ihm haben", en Entwicklungspolitik, EPD, 2/3/1982, pp. 23-28.

“El cesto de los cisnes muertos", en Proposiciones, año 2, N. 6, Mayo, 1982, p. 37. 
"El control de la ciencia en nombre de la cientificidad", en Revista Centroamericana de Economía, No 9, Honduras, 1982, pp. 6-19.

"El criterio de la falsabilidad en las ciencias empíricas", en Assmann, Hugo (de), El sujeto como objeto de las ciencias sociales, CINEP, Bogotá, 1982, pp. 217-235.

"El criterio de la falsabilidad en las ciencias sociales", en El sujeto como objeto de las ciencias sociales, Serie Teoría y Sociedad, No 8, CINEP, Bogotá, 1982.

"Strukturelle Voraussetzungen einer Friedens, Umwelt und Entwicklungspolitik", en Entwicklungspolitik EPD, Materialien IV/82, Frankfurt am Main, 1982, pp. 13-23.

"El capitalismo actual y la justicia social", en Revista Centroamericana de Economía, enero-abril, UNAH, Tegucigalpa, 1983, pp. (Conferencia pronunciada en la Consulta Internacional sobre Empresas Transnacionales y la Misión de las Iglesias del Consejo Mundial de Iglesias, Bad Boll, F.R.G. /nov. 1981, pp. 23-28.).

"Las condiciones económico-sociales del metodismo en la Inglaterra del siglo XVIII", en Duque, José (ed.), La Tradición protestante en la teología latinoamericana, DEI, San José, 1983, pp. 21-29.

"The Economic Roots of Idolatry: Entrepreneurial Metaphysics", en The Idols of Death and the God of Life, Orbis Books, Maryknoll, New York, 1983, pp. 165-193.

"Bekenntnis zu Jesus Christus Widerstand und Befreiung", en Evangelische Studentengemeinde in der BRD und Berlin (West), Stuttgart, 1984, pp. 58-70.

«Die Politik des totalen Marktes», en Kirche im Kapitalismus. Ein Arbeitsbuch. Versammlung von Christen in Wuppertal-Barmen vom 1 bis 3. Juni: Barmen, 1984.

"Die wirtschaftlichen Wurzeln des Götzendienstes. Die Metaphysik des Unternehmers", en Die Götzen der Unterdrückung und der befreiende Gott, Edition Liberación, Münster, 1984, pp. 111-147.

“El realismo en política como arte de lo posible", en Contribuciones, N. 23, Programa FLACSO, Santiago de Chile, enero, 1984.

“Befreiung, soziale Sünde und subjektive Verantwortlichkeit” (“Liberación, pecado social y responsabilidad subjetiva"), en Venetz, Herman-Josef y Vorgrimler, Herbert (eds.), Das Lehramt der Kirche und der Schrei der Armen (La enseñanza de la Iglesia y el grito de los pobres), Edition Exodus y Liberation, Freiburg/Münster, 1985, pp. 60-76.

“Democracia y derechos humanos", en Revista Pasos, N. 1, DEI, Segunda Época, San José, Junio, 1985.

"Democracia y derechos humanos", en Cuadernos de Derechos Humanos. Serie América Latina, Vol.II, N.¹, ISMUN/FUMEC, Ginebra, Octubre, 1986, p. 11.

"La política del mercado total, su teologización y nuestra respuesta", en Revista Pasos, N. 1, Junio, 1985, DEI, Segunda Época, San José, pp. 1-15. En Democracia y totalitarismo, p. 167ss.

"La política del mercado total, su teologización y nuestra respuesta", en David y Goliath, Revista del Consejo Latinoamericano de Ciencias Sociales, Número 48 (especial), año XV, Barmen, 1985, pp 21-32.

“Democracia, estructura económico-social y formación del mundo mítico religioso", en Pasos, $\mathrm{N}^{\mathrm{o}}$ 3, Octubre, DEI, Segunda Época, San José, 1985. Publicado en Democracia y totalitarismo.

"Derechos humanos y democracia", en Hugo Villela (ed.), Los derechos humanos como política, Amerindia, Santiago de Chile, 1985, pp. 87-97. 
"O carisma cristiâo, sua institucionalizaçâo e as reformas: uma tentativa de reflexâo", en Bonino-Santa Ana-Pixley, Hugo Assmann (ed.), Luta pela vida e evangelizaçâo, Ediciones Paulinas, Sâo Paulo, 1985, p. 9.

"Del mercado total al imperio totalitario", en Pasos, No. 6, Managua Junio, 1986. Publicado en Democracia y Totalitarismo.

"Democracia, estructura económico-social y formación de un sentido común legitimador", en Coraggio, José Luis y Deere, Carmen Diana (ed.), La transición difícil, Siglo XXI, México, 1986, pp. 379-401. También en Democracia y totalitarismo, pp.133-166.

"Vom totalen Markt zum totalitären Imperium", en Das Argument, N. 158 , Berlín, Hamburg, Juli/August, 1986.

“¿De la doctrina social a la doctrina social?”, en Pasos, N. ${ }^{\circ}$ 9, DEI, San José, enero, 1987. En Democracia y totalitarismo.

"Economía y teología: el Dios de la Vida y la Vida Humana" en Girardi, Gulio; Forcano, Benjamín y Vigil, José María (Editores), Nicaragua Trinchera Teológica. Para una teología de la liberación desde Nicaragua, Centro Ecuménico Antonio Valdivieso,Managua y Lóguez Ediciones,Salamanca, con dibujos de Maximino Cerezo, 1987, pp. 257-275.

“El carisma cristiano, su institucionalización y la reforma. Un intento de reflexión”, en Democracia y totalitarismo, DEI, San José 1987, p. 231.

"El concepto de lo político según Carl Schmitt", en Lechner, N. (ed.), Cultura política y democratización, CLACSO-FLACSO-ICI, Buenos Aires, 1987, pp. 235-251.

"El Estado de Seguridad Nacional, su democratización y la democracia liberal en América Latina", en Democracia y Totalitarismo, 1987, p. 211.

"El realismo en política como arte de lo posible", en Kritica-Segunda Epoca-, N. ${ }^{\circ} 22$, Separata, Santiago de Chile, diciembre 1986/enero 1987.

"Frente a la cultura de la post-modernidad: proyecto político y utopía", en Pasos, N. . 12, DEI, Segunda Época, San José, Julio, 1987. Incluido en La fe de Abraham y el Edipo occidental. "Frente a la cultura de la post-modernidad: proyecto político y utopía", en David y Goliath, Revista del Consejo Latinoamericano de Ciencias Sociales, N. 52, 1987.

"La división social del trabajo y la reproducción de la vida humana", en Democracia y totalitarismo, 1987, pp. 13-44.

"La historia del cielo: problemas del fundamentalismo cristiano", en Democracia y totalitarismo, 1987, pp. 241-256.

"La teología del imperio", en Alternativa Latinoamericana, No 7, Buenos Aires, 1987, p. 75. "La teología del imperio", en Amanecer, N. 53, noviembre/diciembre, 1987, p. 20.

“La teología del imperio", en Pasos, No 15, DEI, San José, Enero/Febrero, 1988, pp. 21-18.

"Reflexiones sobre la deuda externa de América Latina”, en Pasos, N 14, DEI, Segunda Época, San José, Noviembre-Diciembre, 1987.

"Central America's foreign debt in the context of Latin America", en The external debt, development and international cooperation. Conference of Non Governmental Organisations, Lima, Peru, 25-29 January, 1988, Edition L' Harmattan, París, 1988.

“Democracia y nueva derecha en América Latina”, en Revista Nueva Sociedad, No 98, Buenos Aires, Noviembre-Diciembre, 1988, pp. 104-115.

“Desarrollo, opción preferencial por los pobres y pecado estructural. Reflexiones a partir de la encíclica 'Sollicitudo Rei Soicialis', en AAVV, El pensamiento de Juan Pablo II. Documentos y comentarios, DEI, San José, 1988, pp. 163-178. 
“Enfoque teológico de la deuda externa”, en Pasos, N. 17, San José, mayo/junio, 1988, pp. 11-19. También en Sacrificios humanos y sociedad occidental: Lucifer y la Bestia, como "¿Es lícito pagar la deuda? La deuda en la teología cristiana", pp. 55-94.

"Enfoque teológico de la deuda externa", en Cuadernos del Centro Tiempo Latinoamericano, Córdoba, 1993, p. 34.

"La deuda externa de América Central en el contexto de la deuda de América Latina”, en Controversia, N. ${ }^{\circ}$ 143-144, Bogotá, junio, 1988, pp. 13-105.

"A privatização das funções do estado", en Tempo e Presença, N. ${ }^{\circ}$ 241, São Paulo, mayo, 1989, pp. 31-32.

"Der Schuldenautomatismus - Ein Marshallplan für die Erste Welt", in Verlierer der Weltwirtschaft. Lateinamerika. Analysen und Berichte, Nr. 13, Junius, 1989, Hamburg

“Economía y teología: las leyes del mercado y la fe”, en Pasos, N²3, DEI, San José, Mayo/Junio, 1989, pp. 1-10. Incluido en Cultura de la esperanza y sociedad sin exclusión.

"Leis do mercado e fé", en Dívida externa e igrejas, Conic, Cese, Cedi, Río de Janeiro, Setiembre, 1989.

"Economía y teología: las leyes del mercado y la fe", en Cuadernos del Centro Tiempo Latinoamericano, Córdoba, 1993, p. 5.

"La fe de Abraham y el Edipo occidental" en Ribla, N. 3, San José, 1989,p. 59, también en La fe de Abraham y el Edipo occidental.

"La fe de Abraham y el Edipo occidental", N. 3, DEI, San José, 1989, pp. 81-101.

"Obstáculos y límites a la libertad académica en América Latina", en Pasos, N²6, DEI, San José, Noviembre/Diciembre, 1989.

"Schuldenautomatismus in Lateinamerika", en Widerspruch, Sonderband 2, Zürich, April, 1989, pp. 93-101.

"Schuldenautomatismus in Lateinamerika" en In euren Häusern liegt das geraubte Gut der Armen.

Öconomisch-theologische Beiträge zur Verschuldungskrise, Exodus, Freiburg, 1989, 239 pp.

“El fusil y el olivo", en Polémica N. 10, Segunda Época, San José, 1990, p. 51.

"El sacrificio cristiano", Mimeo, San José, 1990.

"In Erfüllung des Gesetzes ans Kreuz geschlagen”, in Misereor Arbeitshefte zum Hungertuch, Editorial, ciudad, 1990, p. 62.

"La crisis del socialismo y el tercer mundo" en Pasos, N. 30 , DEI, San José julio/agosto, 1990. En Cultura de la esperanza y sociedad sin exclusión

"La crisis del socialismo y el tercer mundo", en Ecuador Debate, N. 23 , Quito, junio, 1991, p. 100.

“La crisis del socialismo y el tercer mundo", en Páginas, Volumen XVI, N. 109 , Lima, 1991, p. 73.

"La crisis del socialismo y el tercer mundo", en Revista Verapaz, N. 25, Valladolid, noviembre, 1991, pp. 80-95.

"La crisis del socialismo y el tercer mundo", en Gracio das Neves, Rui Manuel (ed.), Inmigrantes en el Estado español. Un reto a los Derechos Humanos, a la Democracia y a la Solidaridad, Editorial San Esteban, Salamanca, 1992.

"La crisis del socialismo y el tercer mundo", en Cuadernos del Centro Tiempo Latinoamericano, Córdoba, 1993, p. 1.

"La crítica de la religión en nombre del cristianismo: Dietrich Bonhoeffer", en AAVV., Teología alemana y teología latinoamericana de la liberación. Un esfuerzo de diálogo, Editorial DEI, San José, 1990, pp. 45-65. 
“La libertad académica bajo control en América Latina”, en Nueva Sociedad, N 107, Mayo/ Junio, 1990.

“La privatización de las funciones del estado en América Latina”, en De la lógica del sacrificio a la realización Humana, Encuentro de Economía, Teología y Política, REDLA-CPID, Alajuela, Costa Rica, 1990, p. 21.

"Mercado total y democracia: la democracia y la nueva derecha en América Latina", en El ojo del huracán, Año 1, N. 3, mayo/julio, 1990, p. 4.

“¿Perdón de las ofensas o de las deudas? Los cambios en el padrenuestro", en Tiempo Latinoamericano. Revista Especializada en temas religiosos y sociales, Año VIII, N. 38 , Córdoba, Argentina, Mayo/Junio, 1990, pp. 19-20.

"Relações do estado e mercado na América Latina", en Tempo e Presenta, Año 14, N. 262 CEDI, Río de Janeiro, 1990, p. 45.

"Sociedad occidental in extremis", en Sociedad y Utopía, Año 1, N. 2, Buenos Aires, septiembre, 1990, p. 21. Es el "Prólogo" de La fe de Abraham y El Edipo occidental.

"Solidarität als Parteinahme gegen Unterdrückung und Ausbeutung. Umkehr und Prophetie".

"¿Capitalismo sin alternativas? Sobre la sociedad que sostiene que no hay alternativa para ella", en Pasos, N. 37, DEI, San José, Septiembre/Octubre, 1991, pp. 11-24. Incluido en Cultura de la esperanza y sociedad sin exclusión

“¿Capitalismo sin alternativas? Sobre la sociedad que dice de sí misma que no tiene salida", en Diakonía, XVIII/71, Managua, julio/septiembre, 1994, p. 45.

“Kapitalismus ohne Alternativen?", en Dirmoser, Dietmar (Hrsg.), Markt in den Köpfen. Lateinamerika. Analysen und Berichte 17, Horlemann, Bad Honnef, 1993.

“Kapitalismus ohne Alternativen?”, en Neue Wege N. 9, Jahrgang, septiembre, 1993.

"El mercado como sistema autorregulado y la crítica de Marx", en Herra, Rafael Ángel (ed.), ¿Sobrevivirá el marxismo?, Editorial de la Universidad de Costa Rica, San José, 1991.

"El nuevo rol del estado en el desarrollo latinoamericano", en Brecha, año XI, N. ${ }^{\circ}$ 4, CODEHUCA, San José, abril, 1991, p. 13.

"La Ifigenia del Occidente: el circuito sacrificial en la legitimación occidental”, en Sacrificios Humanos y Sociedad Occidental: Lucifer y la Bestia, pp. 9-54.

"The Sacrificial Cycle as a Justification for Western Domination: the Western Iphigenia in Latin America", en Sacrifice and Humane Economic Life, World Council of Churches Commission on the Churches' Participation in Development, Occasional Paper, N. $7,1992$.

“La legitimación de la dominación en la sociedad occidental: Lucifer y la Bestia", en Sacrificios humanos y sociedad occidental: Lucifer y la Bestia, DEI, San José, 1991, pp. 95-195.

“Nuestro proyecto de nueva sociedad en América Latina. El papel regulador del estado y los problemas de la auto-regulación del mercado", en Pasos, N. ${ }^{\circ} 33$, DEI, San José, enero/ febrero, 1991. Incluido en Cultura de la esperanza y sociedad sin exclusión.

"Nuestro proyecto de nueva sociedad en América Latina. El papel regulador del estado y los problemas de la auto-regulación del mercado", en Revista Centroamericana de Economía, Año 12, N.35, Postgrado centroamericano en economía y planificación del desarrollo, mayo/agosto, 1991, UNAH, Tegucigalpa

"Nuestro proyecto de nueva sociedad en América Latina", en Centro Tiempo Latinoamericano, Córdoba, 1993, p. 16. 
"Our project for the new Society in Latin America: The regulating role of the state and problems of self-regulation in the Market", en Latin America faces the twentyfirst century, Westview Press, Boulder, USA, 1994, p. 12.

"Paradigmas y metamorfosis del sacrificio de vidas humanas", en Assmann, Hugo (ed.), Sobre ídolos y sacrificios. René Girard con Teólogos de la Liberación, DEI, San José, 1991, pp. 157-179.

“Subjetividad y nuevo orden mundial: ¿qué queda después de la guerra de Irak?", en Pasos Número Especial /1, DEI, San José, 1991. Incluido en Cultura de la esperanza y sociedad sin exclusión.

“Das Todesurteil ist bereits gesprochen. Ein Kapitalismus mit demokratischer Fassade bedroht die Welt. Eine Analyse aus lateinamerikanischer Sicht", en Publik-Forum, N. ${ }^{\circ}$ 15, 14, Agosto, 1992, p. 5.

"El desarrollo de América Latina y la cultura de la desesperanza", en Amanecer, N. ${ }^{\circ}$ 79, Agostooctubre, 1992, p. 29.

"El desarrollo de América Latina y la cultura de la desesperanza", en Educación Teológica en Abya-Yala, CETELA, San José, 1992, p. 33.

"La lógica de la expulsión del mercado capitalista y el proyecto de liberación", en Pasos, número especial/3, DEI, San José, Marzo, 1992. Gran parte del artículo está incluido en Cultura de la esperanza y sociedad sin exclusión [como "La lógica de la exclusión del mercado capitalista mundial y el proyecto de liberación"] y en El nihilismo al desnudo. El apartado 3.5 [“La guerra económica”] está únicamente en Pasos.

"Die Ausschlußlogik des kapitalistischen Weltmarktes und der Projekt Befreiung", en 500 Jahre Lateinamerika: Kolonisierung-Wirtschaft-Politik-Religion. Documentation des Symposiums des Graduiertenkollegs 'Interkulturelle religiöse bzw. religionsgeschichtliche Studien', U. Bonn, 1992, p. 65.

"Die Ausschlußlogik des kapitalistischen Weltmarkts: ein lateinamerikanischer Gesichtspunkt”. Ponencia en Instituto Goethe, San Leopoldo, 1993.

«La simetría del neoliberalismo y el estalinismo. ¿Capitalismo sin alternativas?», N. ${ }^{\circ}$ 123, UCA, Managua, febrero, 1992, p. 33.

«Las tareas futuras del Estado, frente al mercado y la sociedad civil», en Eduardo Stein y Salvador Arias, (ed.), Democracia sin pobreza. Alternativa de desarrollo para el istmo centroamericano, DEI, San José, 1992.

«¿Qué es América Latina?», en Misión: carga o desafío para la Asociación Cristiana de Jóvenes, Confederación Latinoamericana de Asociaciones Cristianas de Jóvenes, Buenos Aires, mayo, 1992, p. 7.

"Warum schickt Europa Karavellen? Die Entwicklung der Abhängigkeit" (entrevista), en Beat Dietschy, Ist unser Gott auch euer Gott?, Edition Exodus, Luzerna, 1992, p. 57.

“Wenn die Steine nicht reden, dann müssen wir reden”, in Programm 92-93, Edition Exodus, Luzerna, 1992, p. 8.

"Alternativen zur Marktwirtschaft?", Revista o fuente, Editorial, 1993.

“Capitalismo y socialismo: la posibilidad de alternativas", en Pasos, N. 48, DEI, San José, Julio/ Agosto, 1993, pp. 10-15.

"Pensar en alternativas: capitalismo, socialismo y la posibilidad de otro mundo", en Pixley, Jorge, Por un mundo otro. Alternativas al mercado global, CLAI-DEI, Quito, 2003, pp. 11-28. [Es una versión ampliada del artículo publicado en Pasos, N. ${ }^{\circ} 48$. 
“Crítica al sistema económico capitalista desde la ética", en Evangelio y liberación. XIII Congreso de teología 'Ética universal y cristianismo' 8-12 septiembre, Madrid, 1993, p. 19.

"El cautiverio de la utopía: las utopías conservadoras del capitalismo actual, el neoliberalismo y la dialéctica de las alternativas", en Pasos, N. ${ }^{\circ}$ 50, DEI, San José, Noviembre/ Diciembre, 1993. Incluido en Cultura de la esperanza y sociedad sin exclusión.

"El cautiverio de la utopía: las utopías conservadoras del capitalismo actual", en Christus, México, octubre/noviembre, 1994.

"O cautiveiro da utopia. As utopias conservadoras do capitalismo atual, o neoliberalismo e o espaço para alternativas", en Revista Eclesiástica Brasileira, N. ${ }^{\circ}$ 54, Editorial, Río de Janeiro, 1994.

"Gebrauchwert, Nutzenpräferenz und postmodernes Denken: Die Wertlehre in der Wirtschaftstheorie und ihre Stelle im Denken über die Gesellschaft", en Fornet-Betancourt, Raúl (ed.), Die Diskursethik und ihre lateinamerikanische Kritik. Documentation des Seminars interkultureller Dialog im Nord-Süd Konflikt. Die hermeneutische Herausforderung, Verlag Augustinus-Buchhandlung, Aachen, 1993.

“La teoría del valor de Marx y la filosofía de la liberación: algunos problemas de la ética del discurso y la crítica al marxismo de Apel", DEI, junio, 1993. En El mapa del emperador. "Die Marsche Wertlehre und die Philosophie der Befreiung: einige Probleme der Diskursethik und der Marxismuskritik Apels", en Fornet-Betancourt, Raúl (ed.), Für Enrique Dussel. Aus Anlaß seines 60. Geburtstags, Verlag AugustinusBuchhandlung, Aachen, 1995.

"Nuevo orden mundial y tercer mundo: el desarrollo de América Latina y la cultura de la desesperanza", en Ko'ejú Latinoamericano, N. 64, Año 14, Caracas, abril/junio, 1993, p. 36.

"Changes in the Relationships between Third World Countries and First World Countries", en Abraham, K.C./Mbuy-Beya, Spirituality of the Third World, Bernadette, Orbis Books, New York, 1994.

“Es el antropocentrismo occidental el culpable de la debacle ecológica actual?”, (¿publicación?) UNA, San José, 1994.

"Estado, democracia y cultura de la desesperanza", Cátedra UNESCO/ Facultad de Comunicación, Universidad Javeriana, Mimeo, Bogotá, 1994.

"El desarrollo de América Latina y la cultura de la desesperanza", en CEBs Informativo,

Boletín N. 21, julio/agosto/septiembre, 1994, p. 14. [Síntesis del planteamiento de FJH en reunión celebrada en julio de 1994, en Colombia].

“Estado y poder político en América Latina: el desarrollo de América Latina y la cultura de la desesperanza", Universidad de Santo Tomás, Bogotá, 1994.

"Ética do discurso e ética de responsabilidade: uma toma de posição critica", en Sidekum, Antonio (ed.), Ética do discurso e filosofia da libertação. Modelos complementares, Ed. Unisinos, Sao Leopoldo, 1994.

"Diskursethik und Verantwortungsethik: eine kritische Stellungnahme", en FornetBetancourt, Raúl (ed.), Konvergenz oder Divergenz? Eine Bilanz des Gesprächs zwischen Diskursethik und Befreiungsethik, Verlag Augustinus-Buchhandlung, Aachen, 1994.

“La teología de la liberación en el contexto económico-social de América Latina: economía y teología o la irracionalidad de lo racionalizado", en Cristianismo y Sociedad, N. ${ }^{\circ}$ 120, Guayaquil, junio, 1994, p. 59. 
"La teología de la liberación en el contexto económico-social de América Latina: economía y teología o la irracionalidad de lo racionalizado", en Pasos, N. 57, DEI, San José enero/febrero, 1995. Incluido en Cultura de la esperanza y sociedad sin exclusión.

"La teoría de la modernidad y el pensamiento de Marx. Algunas reflexiones sobre un libro de Jaques Bidet", inédito, San José, octubre de 1994.

"América Latina y el fin de siglo", en Revista Nueva Sociedad, N. 139, Venezuela. SeptiembreOctubre, 1995, en la sección "América Latina: la visión de los cientistas sociales".

"Una sociedad en la que quepan todos: de la impotencia de la omnipotencia", en Pasos, N. . 60, DEI, San José, Julio/Agosto, 1995, pp. 1-13. Incluido en Cultura de la esperanza y sociedad sin exclusión.

"Utopía, anti-utopía y ética. La condición postmoderna y la modernidad", ponencia presentada en alemán en Eichstätt, en el diálogo con Karl-Otto Apel, abril de 1995 [En El mapa del emperador, pp. 83-187]

“Vom Marktwert der Arbeit vom Wert des Menschen”, en Kirchentag 95: gesehen-gehort-erlebt, Gutersloher Verlag-Haus, 1995, pp. 150.

“Determinismo y autoconstitución del sujeto: Las leyes que se imponen a espaldas de los actores y el orden por el desorden", en Pasos, N 64, DEI, San José Marzo/ Abril, 1996. Incluido en El mapa del emperador

"Los muertos en el sótano del occidente: la metafísica de la inhumanidad y nuestra respuesta", en Pasos, N 67, San José, Septiembre/Octubre, 1996, pp. 24-30.

"Wider die verfertigten Götzen der Macht. Zur Metaphysik der okzidentalen Unmenschlichkeit", en Jahrbuch politische Theologie, Bd.2, LIT, Münster, 1997.

"América Latina y la Globalización de los mercados", en Dieterich, Heinz (coord.), Globalización, exclusión y democracia en América Latina, Contrapuntos-Joaquín Mortiz, México, 1997, pp. 113-131.

"El asesinato es un suicidio: de la utilidad de la limitación del cálculo de utilidad", en Pasos, N 74, DEI, San José Noviembre/Diciembre, 1997. Incluido en El grito del sujeto.

"El asesinato es un suicidio: de la utilidad de la limitación del cálculo de utilidad", en Utopías, nuestra bandera: revista de debate político, No. 178, Partido Comunista de España, 1998, pp. 133-153.

“El huracán de la globalización: la exclusión y la destrucción del medio ambiente vistos desde la teoría de la dependencia", Pasos, N. 69 , DEI, San José enero/febrero, 1997. En El huracán de la globalización.

"La doctrina social de la iglesia y su desarrollo postconciliar", en Pasos, No 72, DEI, San José, Julio/Agosto, 1997, pp. 1-8.

"El proceso de globalización y los derechos humanos: la vuelta del sujeto", en Pasos, N 79, DEI, San José, Septiembre/Octubre, 1998. Incluido en El nihilismo al desnudo [es la última versión] y en El huracán de la globalización.

"El proceso actual de globalización y los derechos humanos: la vuelta del sujeto", en

Herrera Flores, Joaquín (Ed.), El vuelo de Anteo. Derechos humanos y crítica de la razón liberal, op. Cit., Desclée de Brouwerpp, Bilbao, 2000, pp. 117-127. En esta publicación hay un apartado [“Una reflexión crítica desde la tradición cristiana", pp. 126-127] que no aparece en las otras versiones.

"Globalisierung und Ausschluß aus Lateinamerikanischer Sicht”, en Fornet-Betancourt, Raúl (ed.), Armut im Spannungsfeld zwischen Globalisierung und dem Recht auf eigene Kultur: 
Dokumentation des VI. Internationalen Seminars des philosophischen Dialogprogramms, IKO, Fráncfort, 1998, pp. 92-104.

“¿Hay una salida al problema de la deuda externa?", en Pasos, N 82, DEI, San José, Marzo/ Abril, 1999, pp. 8-19. En El huracán de la globalización.

"La inversión de los derechos humanos: el caso de John Locke", en Pasos, N 85, DEI, San José, Septiembre/Octubre, 1999. En El sujeto y la ley y en ¿Quieren el mercado total? El totalitarismo del mercado.

"La inversión de los derechos humanos: el caso de John Locke", en Herrera Flores, Joaquín (Ed.), El vuelo de Anteo. Derechos humanos y crítica de la razón liberal, Desclée de Brouwer, Bilbao, 2000.

"Prólogo", en El huracán de la globalización, DEI, San José, 1999, pp. 13-15.

"Derechos humanos como distorsiones del mercado que hay que eliminar", 2000, en http:// www.una.ac.cr/ambi/revista/81/Hinkelammert.htm . La mayor parte de este artículo ha sido publicada también en Solidaridad o suicidio colectivo, pp. 13-16.

"La vuelta del sujeto reprimido frente a la estrategia de la globalización (Síntesis del encuentro de cientistas sociales y teólogos/as: La problemática del sujeto en el contexto de globalización)", en Pasos, No 87, DEI, San José, Enero/Febrero, 2000, pp. 4-6. Publicada en El sujeto y la ley y en El nihilismo al desnudo. Además, se encuentra la síntesis del debate de FJH con otros participantes, pp. 6, 36-38.

"Globalización como ideología encubridora: Desfigura y justifica los males de la realidad actual", en Concilium: Revista internacional de teología, N² 293, España, 2001, pp. 29-38. [Ejemplar dedicado a la globalización y sus víctimas]

"Globalización y derechos humanos frente al Estado de bienestar", conferencia pronunciada el 18 de abril de 2001, en la Universidad Nacional (UNA), Heredia. Un pequeño fragmento de esta conferencia ha sido publicado en El nihilismo al desnudo, pp. 237-238.

“La caída de las torres", en Pasos, N 98, DEI, San José Noviembre/Diciembre, 2001. En El sujeto y la ley.

"La caída de las torres", en Polis: revista académica de la Universidad Bolivariana, No 4 , Santiago de Chile, 2003.

"El socavamiento de los derechos humanos en la globalización actual: La crisis de poder de las burocracias privadas", en Realidad. Revista de Ciencias Sociales y Humanidades, 87, UCA, San Salvador, Mayo-Junio, 2002, pp. 315-330. También publicada en El asalto al poder mundial y la violencia sagrada del imperio.

"La crisis de poder de las burocracias privadas: el socavamiento de los derechos humanos en la globalización actual", en Revista de Filosofía, N. ${ }^{\circ} 40$, Universidad del Zulia, Maracaibo, Enero-Abril, 2002, pp. 15-33.

“Plenitud y escasez: la subjetividad y el reino de Dios", en Pasos, N. 100, DEI, San José, 2002, pp. 3-11. Publicado en El asalto al poder mundial y la violencia sagrada del imperio y en El sujeto y la ley, como "Plenitud y escasez: quien no quiere el cielo en la tierra, produce el infierno".

"Plenitud y escasez: quien no quiere el cielo en la tierra, produce el infierno", en Polis: revista académica de la Universidad Bolivariana, N.o 8, 2004.

"La proyección del monstruo: la conspiración terrorista mundial", en Pasos, No 101, DEI, San José, Mayo/Junio, 2002. En El asalto al poder mundial y la violencia sagrada del imperio.

“El sujeto negado y su retorno", en Pasos, N 104, DEI, San José, Noviembre/Diciembre, 2002, pp. 1-12. Probablemente es el desarrollo de una ponencia homónima que fuera publicada 
posteriormente, en Pasos, N. ${ }^{\circ}$ 106, 2003, pp. pp. 4-8, que Hinkelammert leyó en el Encuentro de Cientistas Sociales y Teólogos, celebrado en el DEI, San José, del 5 al 9 de diciembre de 2002. El artículo sería publicado finalmente en El asalto al poder mundial y la violencia sagrada del imperio (pp. 271-294), como “El sujeto, el anti-sujeto y el retorno del sujeto (interculturalidad y fundamentalismo)

"Estancamiento dinámico y exclusión en la economía mundial", Herramienta, 22, Buenos Aires, 2003,. [26 de Marzo de 2014: http://www.herramienta.com.ar/revista-herramientan-22/estancamiento-dinamico-y-exclusion-en-la-economia-mundial]

“Introducción", en Pixley, Jorge, Por un mundo otro. Alternativas al mercado global, op. Cit., Quito, Departamento de Comunicaciones del Consejo Latinoamericano de Iglesias, 2003, pp. 7-9.

"La negación del sujeto en los fundamentalismos y la raíz subjetiva de la interculturalidad" (Síntesis del Encuentro de Cientistas Sociales y Teólogos, celebrado en el DEI, San José, del 5 al 9 de diciembre de 2002), Pasos, N. 106, DEI, San José, 2003, pp. 4-72. En este texto encontramos la síntesis del debate de FJH con otros participantes (pp. 12-14, 24, 59, 63-71).

“La guerra de Irak: el asalto al poder sobre el mundo", en Pasos, N. 107, DEI, San José, 2003, pp. 17-31. Fue publicado en El asalto al poder mundial y la violencia sagrada del imperio, como "La guerra contra Irak: el asalto al poder sobre el mundo".

"La guerra de Irak: el asalto al poder sobre el mundo", en Soriano, Ramón Luis, Mora Molina, Juan José (Coord.), El nuevo orden americano: ¿la muerte del derecho?, Editorial Almuzara, España, 2005, pp. 101-112.

“La vida es más que el capital. La democracia de ciudadanos y el proyecto de la sociedad en la que quepan todos los seres humanos", en Pasos, No 113, DEI, San José, Mayo/Junio, 2004, pp. 12-16.

“La vida es más que el capital. La democracia de ciudadanos y el proyecto de la sociedad en la que quepan todos los seres humanos", en Revista Rábida, № 23, Diputación provincial de Huelva, 2004, pp. 65-70.

"La transformación del estado de derecho bajo el impacto de la estrategia de Globalización", en Pasos No 117, DEI, San José, Enero/Febrero, 2005, pp. 4-11.

"La transformación del Estado de derecho bajo el impacto de la Globalización", en las actas del XI Congreso Internacional de Filosofía Latinoamericana. Hermenéutica analógica, democracia y derechos humanos, Universidad Santo Tomás, Bogotá, 2005, pp. 124-141. Hay un resumen de la participación de FJH en un panel, en la página 238.

"La transformación del estado de derecho bajo el impacto de la estrategia de Globalización", en Polis: revista académica de la Universidad Bolivariana, No. 10, Santiago de Chile, 2005.

"La transformación del Estado de Derecho bajo el impacto de la estrategia de la globalización", en Hoyos Vásquez, Guillermo (compilador), Filosofía y teorías políticas, entre la crítica y la utopía, CLACSO, Buenos Aires, 2007.

“La universidad frente a la globalización”, en Polis: revista académica de la Universidad Bolivariana, No. 11, Santiago de Chile, 2005.

"Prometeo, el discernimiento de los dioses y la ética del sujeto. Reflexiones a partir de un libro", en Pasos N ${ }^{\circ}$ 118, DEI, San José, Marzo/Abril, 2005, pp. 7-24. En Hacia una crítica de la razón mítica. 
"Prometeo, el discernimiento de los dioses y la ética del sujeto. Reflexiones a partir de un libro", en Utopía y praxis latinoamericana: revista internacional de filosofía iberoamericana y teoría social, No. 31, Universidad del Zulia, Venezuela, 2005, pp. $9-36$

"Prometeo, el discernimiento de los dioses y la ética del sujeto: Reflexiones sobre un mito fundante de la modernidad", en Polis: revista académica de la universidad Bolivariana, N 13, Santiago de Chile, 2006.

"Prometeo, el discernimiento de los dioses y la ética del sujeto. Reflexiones sobre un mito fundante de la modernidad", en Fernández Estela y Vergara, Jorge (eds.); Racionalidad, utopia y modernidad. El pensamiento crítico de Franz Hinkelammert. Homenaje en sus 75 años, Universidad Bolivariana, Santiago de Chile, 2007, pp. 157-194.

[Sin título], ponencia breve en el Foro Público "Filosofía, política e imperialismo", en el marco del Primer Foro Internacional de Filosofía de Venezuela, en la Universidad Central de Venezuela, el 8 de julio de 2005, publicada en Memorias del I Foro Internacional de Filosofía de Venezuela, Caracas, Ministerio de la Cultura/ Red de Intelectuales y Artistas en Defensa de la Humanidad, 2006, pp. 42-43.

“El mercado neoliberal como mediador de salvación”, en Revista Éxodo, No. 86, Centro Evangelio y Liberación, Madrid, 2006, pp. 44-45.

"La globalidad de la tierra y la estrategia de la globalización", en Borón, Atilio y González, Amadeo (compiladores), La teoría marxista hoy. Problemas y perspectivas, CLACSO, Buenos Aires, 2006, pp. 365-378. [Parece ser que es un artículo modificado de un capítulo publicado en El grito del sujeto (1998)].

"Reflexiones sobre Nietzsche (Respuesta a “¿Con Nietzsche contra Nietzsche? Una discusión con Franz Hinkelammert", de José Manuel Romero)", en Realidad. Revista de Ciencias Sociales y Humanidades, N. ${ }^{\circ}$ 107, UCA, San Salvador, Enero-Marzo, 2006, pp. 101-115.

"Reflexiones sobre Nietzsche (Respuesta al texto "Hinkelammert y Nietzsche" de José Manuel Romero)", en Fernández Estela y Vergara, Jorge (eds.); Racionalidad, utopía y modernidad. El pensamiento crítico de Franz Hinkelammert. Homenaje en sus 75 años, Universidad Bolivariana, Santiago de Chile, 2007, pp. 423-437.

"La inversión de los derechos humanos por medio de la construcción de monstruos", en Fernández Estela y Vergara, Jorge (eds.); Racionalidad, utopía y modernidad. El pensamiento crítico de Franz Hinkelammert. Homenaje en sus 75 años, Universidad Bolivariana, Santiago de Chile, 2007, pp. 139-156.

"Pensamiento crítico y crítica de la razón mítica", en Pasos, No 130, DEI, San José, Marzo/Abril, 2007, pp. 42-46. En Hacia una crítica de la razón mítica.

"Pensamiento crítico y crítica de la razón mítica", en Theologica Xaveriana. Revista de la Facultad de Teología de la Pontificia Universidad Javeriana, N 163, Bogotá, 2007, pp. 399-412.

"El juego de las locuras: Ifigenia, San Pablo y el pensamiento crítico", en Pasos, $\mathrm{N}^{\circ} 140$, Noviembre/Diciembre, DEI, San José, 2008, pp. 1-16. En La maldición que pesa sobre la ley. "El juego de las locuras: Ifigenia, San Pablo y el pensamiento crítico", en Realidad.

Revista de Ciencias Sociales y Humanidades, No 121, UCA, San Salvador, JulioSeptiembre, 2009, pp. 487-509.

"Humanismo y violencia", en Polis: revista académica de la Universidad Bolivariana, No. 18, Santiago de Chile, 2008. 
"Humanismo y violencia", en Memorias del III Foro Internacional de Filosofía de Venezuela. Humanismo, socialismo y revolución, Ministerio del Poder Popular para la Cultura/ Red de Intelectuales y Artistas en Defensa de la Humanidad, Venezuela, 2008, pp. 477-485.

"Sobre la reconstitución del pensamiento crítico", en Polis: revista académica de la Universidad Bolivariana, No. 21, Santiago de Chile, 2008. En La maldición que pesa sobre la ley.

"Sobre la reconstitución del pensamiento crítico", en Realidad. Revista de Ciencias Sociales y Humanidades, No. 115, UCA, San Salvador, Enero-Marzo, 2008, pp. 35-64.

"La crítica de la ley en la modernidad", Parece que era originalmente un capítulo de La maldición que pesa sobre la ley: las raíces del pensamiento crítico en Pablo de Tarso. Arlekín, San José, 2010.

“La vigencia actual de 'El Capital'”, conferencia inaugural de la Cátedra Virtual de Diálogo e Investigación Karl Marx, Universidad Nacional de Costa Rica, Heredia, 2009.

“Respuesta a Antonio Salamanca Serrano: La verificación de la satisfacción de las necesidades materiales [como] criterio para juzgar el utilitarismo, el consecuencialismo y la ética del bien común", marzo, 2009.

“El sujeto y la ley: el retorno del sujeto reprimido", en Utopía y praxis latinoamericana: revista internacional de filosofía iberoamericana y teoría social, N. 48 , El perro y la Rana, Maracaibo, 2010, pp. 125-137.

"Lo indispensable es inútil. Sobre la ética de la convivencia", en Revista de filosofía, Vol. 68, No. 2, Chile, 2011, pp. 30-58.

"Coyuntura latinoamericana y mundial: el pesimismo esperanzado", en Cuadernos del Pensamiento Crítico Latinoamericano, N. . 56, agosto-septiembre, 2012, CLACSO.

"Coyuntura latinoamericana y mundial: el pesimismo esperanzado", en Le Monde Diplomatique en español, No. 203, Cybermonde, España, 2012, pp. 21-22 (Ejemplar dedicado a: Suplemento: World Forum for Democracy. Venezuela de cara al futuro).

"Coyuntura latinoamericana y mundial: el pesimismo esperanzado", en La Jornada, de México, Página/12, de Argentina, y Le Monde Diplomatique, de Bolivia, Chile y España, 2012.

"La rebelión de los límites, la crisis de la deuda y el vaciamiento de la democracia y el genocidio económico-social", en Pasos, No 155, Tercera Época, DEI, San José, Abril/Junio, 2012, pp. 10-26.

“La rebelión de los límites, la crisis de la deuda y el vaciamiento de la democracia”, en Realidad. Revista de Ciencias Sociales y Humanidades, No 132, UCA, San Salvador, Abril-Junio, 2012, pp. 231-250 [En ¿Quieren el mercado total? El totalitarismo del mercado].

"El capitalismo como religión", inédito 2013 [algunos fragmentos se encuentran en ¿Quieren el mercado total? El totalitarismo del mercado]

“El vaciamiento de los derechos humanos en la estrategia de globalización (La perspectiva de una alternativa)",,., inédito, 2016, 16 p. [es un desarrollo más amplio de algunos elementos que se encuentran en el capítulo $\mathrm{V}$ de ¿Quieren el mercado total? El totalitarismo del mercado]. 
“Mecanismos de funcionamiento y banalización del mundo", inédito 2016, 18 p. [es un desarrollo más amplio de elementos que se encuentran en el capítulo IV de ¿Quieren el mercado total? El totalitarismo del mercado].

\section{Referencias y documentos sobre los que no hay mucha información}

"Manuscritos de libros"Cfr. Duque, José y Gutiérrez, Germán (eds.), Itinerarios de la razón crítica: Homenaje a Franz Hinkelammert en sus 70 años, p. 23.

"Texto de un curso, elaborado por los estudiantes", Cfr. Duque, José y Gutiérrez, Germán (eds.), Itinerarios de la razón crítica: Homenaje a Franz Hinkelammert en sus 70 años, Chile y otros, 1963 o después p. 26.

"Documento del CEREM", Santiago, 1973, 18 pp.

"Die Einsamkeit der Dritten Welt". Drei Thesen von Franz J. Hinkelammert, en: Lateinamerikatage '91. Berlin. p. 9, [Hay una referencia a Franz en el cartel de eventos de Lateinamerikatage '91, año 1991, http://www.fdcl-berlin.de/?id=647 Pero en los carteles no hay referencia al título ("Die Einsamkeit der Dritten Welt"). Busqué y encontré que ese es el nombre de un libro de Helmut Thielen, no de Franz. Probablemente, Thielen cita a Franz]

“Texto sobre el 'panorama de la teología de la liberación' y sobre Marx como un 'Aristóteles de los siglos XIX y XX', volumen colectivo” Cfr. Duque, José y Gutiérrez, Germán (eds.), Itinerarios de la razón crítica: Homenaje a Franz Hinkelammert en sus setenta años, pp. 32 y 87. "El papel regulador del Estado y los problemas de la auto-regulación del mercado", Mimeo, 13 pp.

"Es fehlt ein 'nein' zur Schuldenrückzahlung", en Entwicklungspolitik, (Dokumentation " $\mathrm{r}$ "). Metodología positivista y dialéctica, ILADES, Santiago.

Ideologie und wirtschaftliches handeln.

Utopie und Ethik.

Von Marx zu Nietzsche.

\section{Semblanza por}

Estela Fernández Nadal. Argentina, profesora y doctora en Filosofía por la Universidad Nacional de Cuyo, Mendoza, Argentina (1983 y 1995, respectivamente). Actualmente se desempeña como investigadora principal del Consejo Nacional de Investigaciones Científicas y Técnicas de Argentina, y como profesora titular ordinaria de filosofía en la carrera de Sociología, de la Facultad de Ciencias Políticas y Sociales de la Universidad Nacional de Cuyo. Anteriormente, se desempeñó como directora de la Maestría en Arte Latinoamericano y del Doctorado en Arte Latinoamericano, ambas carreras de Posgrado de la Facultad de Artes y Diseño de la Universidad Nacional de Cuyo. Entre sus publicaciones destacan: Revolución y utopía. Francisco de Miranda y la independencia hispanoamericana (Mendoza, EDIUNC, 2001); Itinerarios socialistas en América Latina (Córdoba, Alción, 2002); Racionalidad, modernidad y utopía. El pensamiento crítico de Franz Hinkelammert (en colaboración con Jorge Vergara; Santiago 
de Chile, Universidad Bolivariana, 2007) y Teología profana y pensamiento crítico. Conversaciones con Franz Hinkelammert (en colaboración con Gustavo Silnik, Buenos Aires, CLACSO y CICCUS, 2012).

Contacto: esfer@speedy.com.ar; empernan@mendoza-conicet.gob.ar

\section{Bibliografía por}

Carlos Molina Velásquez. Salvadoreño, obtuvo su doctorado en Filosofía Iberoamericana por la Universidad Centroamericana José Simeón Cañas (UCA). Se desempeña como profesor en las áreas de ética, pensamiento crítico y cultura contemporánea, en el Departamento de Filosofía de la UCA. Es editor de los volúmenes segundo (1999) y tercero (2001) de los Escritos Filosóficos de Ignacio Ellacuría y autor de los libros Ética profesional y organizacional (2012) y Cuerpo, ley y sacrificialidad. La antropología crítica de Franz J. Hinkelammert (en prensa). Forma parte del Consejo Editorial de la revista académica Realidad. Revista de Ciencias Sociales y Humanidades (UCA), es miembro del equipo de investigación internacional "Grupo Pensamiento Crítico", de la Comisión Nacional de Bioética de El Salvador (CNBES) y de la Redbioética UNESCO. También es coordinador del Capítulo Salvadoreño de la Red de Intelectuales, Artistas y Movimientos Sociales en Defensa de la Humanidad.

Contacto: camolina@uca.edu.sv 
